\title{
PAEDIATRIC ANTIRETROVIRAL THERAPY \\ Beyond the Guidelines
}

\author{
Leon J Levin, MB BCh, FCPaed (SA), DTMEH \\ Medical men don't know the drugs they use nor their cost.' \\ Roger Bacon, 1214-1294
}

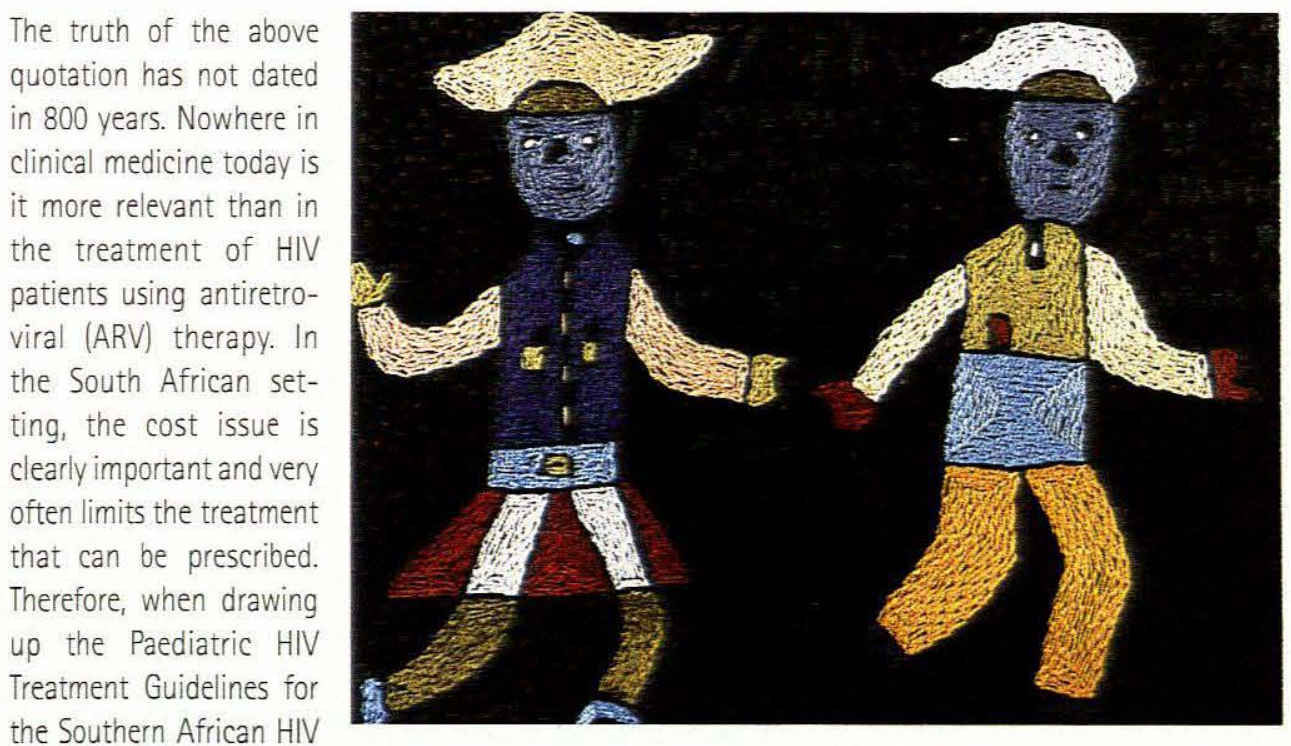
the Southern African HIV Clinicians Society, consideration was given to the fact that treatment options might vary from state-of-the-art combinations to cheaper options suitable for use in a resourcelimited setting.

Indeed, it is felt that in some aspects these guidelines are more progressive than the American guidelines. A recent exciting development, addressed in the Society's Guideline but not elsewhere, is the treatment of infants under 3 months of age. Since most of these patients acquire their infection at around the time of birth, we really are dealing with acute primary HIV infection. These children have a good response to therapy, and viral suppression may be so significant that they develop a normal, functioning immune system. At the age of about 18 months, when infected children normally lose their maternal HIV antibodies, the HIV ELISA can become negative (the DNA PCR, however, remains positive). This reflects the extent to which their virus is suppressed and hidden from the immune system, thus minimising an antibody response. Although the numbers of children are small, there is a definite suggestion that these results are achieved more readily with a 4-drug regimen than a 3-drug regimen ( $K$ Luzuriaga - personal communication); hence the inclusion of a 4-drug regimen in the Guidelines for patients under 3 months of age.

Another important difference in the Society's Guideline is that the dosage regimens incorporate the latest pharmacokinetic data and therefore dosages occasionally differ from those found in the drug package inserts. Because infants and children metabolise their drugs at a faster rate than adults, relatively larger dosages are necessary in this patient group.

Consideration was given to utilising the international guidelines, with modifications, for the South African setting encourage paediatricians to further their knowledge in this fascinating, complex and ever-changing field.

In this vein, it is perhaps sad that there are so few paediatricians in South Africa actively involved in treating patients with ARV drugs. The Paediatric Subcommittee of the Southern African HIV Clinicians Society is uniquely poised to help transport our paediatricians 'beyond the guidelines'. Lectures and workshops on ARV therapy, run by experienced paediatricians and other clinicians, are available through the Society on request. Additionally, the Society is happy to respond to any queries that might arise on paediatric ARV therapy, and has access to an extensive network of international paediatricians for consultation. It is hoped that the Paediatric HIV Treatment Guidelines will prove a useful companion in practice.

For more information on the activities of the Paediatric Subcommittee of the HIV Clinicians Society, contact the society directly, or the following:

$\begin{array}{lll}\text { Mark Cotton: } & \text { e-mail } & \text { mcot@gerga.sun.ac.za } \\ \text { Glenda Gray: } & \text { e-mail } & \text { gray@pixie.co.za } \\ \text { Leon Levin: } & \text { e-mail } & \text { ethbil@netactive.co.za }\end{array}$

REFERENCES

The Working Group on Antiretroviral Therapy and Medical Management of HIV-infected Children convened by the National Pediatric and Family HIV Resource Center (NPHRC), the Health Resources and Services Administration (HRSA), and National Institutes of Health (NIH). Guidelines for the use of Antiretroviral Agents in Pediatric HIV Infection. Published and updated regularly on the web. www.hivatis.org.

2. Luzuriaga K, et al. J Virol 2000; 74:6984-6991. 